\title{
Seating Arrangements as a Means for Improving Interactions in EFL Beginner Classes: The Case of Some Secondary Schools in Littoral Region
}

\author{
Pédro Marius Egounléti, Ulrich O. Sèna Hindémè, Innocent C. Datondji \\ Université d'Abomey - Calavi, Bénin \\ *Corresponding Author: Ulrich O. Sèna Hindémè, Université d'Abomey - Calavi, Bénin
}

\begin{abstract}
With the implementation of the learner-centered curriculum and its related tasks in Beninese secondary schools since 2000, a large majority of EFL teachers are often confronted with the problem of determining the seating arrangement which garbs their teaching and learning objectives. This research work is to determine which arrangements of desks best facilitate and boosts interaction between EFL learners in Beninese secondary schools. Data was gathered through a two-part questionnaire distributed to 100 EFL teachers selected randomly in some secondary schools in Littoral region. The results collected indicate that Beninese EFL teachers resort to different seating arrangements during their classes and the choice of a seating arrangement affects interaction between and among EFL beginners in various ways. Seating arrangements, as important classroom setting events, have the potential to help prevent behavior problems that decrease student's attention and diminish available instructional time. Evidence supports the idea that students display higher levels of appropriate behavior during individual tasks when they are seated in rows, with disruptive students benefiting the most. As a result, EFL teachers should let the nature of the task dictate seating arrangements.
\end{abstract}

Keywords: Seating Arrangement, Improving, Interaction, EFL, Classes

\section{INTRODUCTION}

No one can forget his childhood classrooms and might remember racing his peers to class on the first day to get his favorite seat in the second row by the window. He was convinced that seating there would give him the best chance to earn a great grade and impress the teacher, and it could only be more perfect if his best friend got there in time to sit in the seat next to him. Research has shown that student participation in class activities is affected by a number of factors that include students' gender, personality differences as well as class environment. This class environment includes classroom seating arrangements which are believed to play an important role in fostering students' performance in classroom. Seating arrangements are important classroom setting events because they have the potential to help prevent behavioral problems that decrease student attention and diminish available instructional time. However, how a seating arrangement can encourage on-task behaviour is found to depend on how far this seating arrangement agrees with the activity being done and the interaction pattern aimed at in class. The idea of classroom seating arrangement is therefore of great importance since it can be one of the factors that either encourage or inhibit students' on-task participation in language classes. The seat location not only affected students' academic performance, but it influenced their motivation to succeed.

If that seating location affects a student's ability to perform in the classroom, then educators should spend more time organizing their learning environments to support achievement for all students. Most EFL teachers do not undergo formal seating chart training in their classes, so perhaps they are not aware of the factors required to make a good seating chart. Students learn in different ways, just as their teachers develop customized skills to incorporate instructional methods that work best for them. There is no "one size fits all" solution to creating effective seating arrangements. The purpose of this study is to determine how classroom seating arrangements can affect student on-task participation in EFL classes and in what ways seating arrangements can improve interaction among EFL students.

\section{Problem Statement and Purpose of The Study}

Students spend a large amount of time in a classroom where desks are arranged in a specific way and individual seats are determined by the teacher. At the beginning of the school year, as part of the 
classroom management, teachers face the question of how and where their students have to seat in classroom setting. This is an important decision, as classroom seating arrangements influence classroom climate and students relationship with each other (Van den Berg et al; 2012; Gest and Rodkin 2011; McKeown et al. 2015). In addition, the physical space of the classroom influences learning and impacts teachers' and students' attitude towards school (Denton 1992). However, it's far from clear what consideration teachers have when making seating arrangements. This insight may help teachers to make (even) more structured and considered decisions resulting in more effective seating arrangements and less concerns for teachers about how to arrange the classroom in a good way. It can also stimulate a better academic and social development for the students.

Effective communication in the classroom is essential to the success of both the student and the teacher. The kind of communication as well as the amount of communication that occurs in the classroom has long been thought to be partially a function of the seating arrangement of the students. Beninese secondary schools has been focussed for a long time in the teaching and learning process, on individual study and evaluation and on the teacher's absolute control over the class. In this regard, the row seating mode has been used for a long time. As a result, teachers succeeded in getting their message across the learners of English. But the point is that the majority of those students, though they got interesting grades in the language, proved unable to use the language to perform everyday communication purposes because they were not accustomed to interaction and realistic situations in the classroom. To address this issue, the communicative language teaching approach has been introduced. This system induced changes in seating arrangements in the classroom. That is why now, apart from row seating, it is common to see students working in groups in the classroom.

This paper also explores the correlation between EFL students' seating location and their performance. To this end, the research intends to provide answers to the following research questions:

- how do Beninese EFL teachers select learners' seating arrangement in the Littoral region?

- To what extent, can EFL learners' seating arrangement affect learners' interaction according to teachers?

\section{LITERATURE REVIEW}

A plethora of research has shown that student interaction in classroom is affected by a number of factors that include students' gender, personality differences as well as class environment. This class environment includes classroom seating arrangements which are believed to play an important role in fostering students' interaction as well as their language performance. However, limited research was found on how to use suitable seating arrangements that could boost students' interaction in class context. Most of the studies found in the field of seating arrangement and classroom furniture either focused on students' on-task behavior in relation to different seating arrangements (Anderson, 2009; Bonus \& Riordan, 1998; McCaskey\& McVetta, 1978; Rosenfield, Lambert \& Black, 1985) On the other hand, some research linked teachers' choice of different classroom seating arrangements and their beliefs in their role inside the class and the institution's views and concepts concerning learning and teaching.

There are three styles that are commonly used in the classroom: traditional rows, U-shaped, and cluster (groups/pairs). Each has their own pros and cons, and each should be weighed carefully to meet the objectives of the lesson and the style of the educator.

Keep in mind, there are other factors involved the educator may not have control over. For example, if the classroom is small, then the options for seating may be limited. Or the "desk" available in the classroom may not be the traditional desk, but a large table to accommodate multiple students.

\subsection{U-Shape Arrangement}

The first seating arrangement is the U-shape design. "In the U-shape configuration, students tend to engage in a higher level of interactive verbal behaviours' according to Wengel (1992). But, this arrangement also enabled teachers to use the behaviours in ways that made their lesson presentation more active and collaborative. The U-shape facilitates interaction between the teacher and the students, and among the students themselves. The results suggest that this seating arrangement influences participation, thinking, and appropriate comments, which in turn have a positive effect on learning (Wengel, 1992). According to Papalia (1994), "the U-shape 
design is found to facilitate the following: teacher mobility, eye contact, pupil attention, communication, game playing, and teacher control".

Again, U-shape depends on the type of class, classroom size, and number of students. It may take some old fashion ingenuity to make it work.

\subsubsection{Interaction}

Interaction is greatly facilitated in this seating arrangement. Students are naturally engaged as they feel part of a larger group instead of just a single speck within a large frame.

Also, the educator can occupy the centre of the group to do experiments or demonstrations so students can easily see and be engaged by the lesson.

Another benefit to this arrangement, the teacher can use a talking instrument, such as a stick, and pass it around the group and have the student holding the item talk. This gives everyone an opportunity to speak and really encourages the others to listen as they are looking eye to eye with the speaker. Psychologically, it is easier for a listener to tune out if they can't see the person that is speaking; this arrangement encourages listening as the listener may not want to be perceived as rude.

\subsubsection{Atmosphere}

Whereas the tradition row was isolating, this arrangement is more welcoming to become part of a greater whole. Connecting with the educator and other students is greatly increased, which in turn, can greatly facilitate interaction and discussion amongst the students. In a way, it promotes togetherness and really helps students engage in the roles of speaker and listener. The student is able to move into the role of participant and take control of his learning and participation.

This arrangement can also provide a positive environment and reassurance for expressing ideas. therefore, when a student opens up to express himself, this natural agreement can become encouragement for the student to share more of his thoughts. In this way, the set up becomes an enabler to students who may otherwise stay quiet.

\subsubsection{Behaviour}

For the educator who has to deal with behavioural problems, this can be a great arrangement to control students. Now, students don't only have to be concerned with the educator seeing them, but now the whole class can see them. Having to be a responsible member of the group can be enough to curtail most problems students usually cause. Also, students are in sense pressured to be engaged for the same reason.

On the other hand, this normally works well with older students who have a sense of responsibility. Putting a class of five year olds in the U-shaped arrangement and expecting it to help with behavioural problems is destined to fail as it will cause more problems. Students at that age don't have a sense of responsibility or understand peer pressure to conform to the group.

\subsubsection{Strategy}

One strategy the educator can utilize to increase student participation and discussion is sitting down. If the educator stands up, then the educator can be seen as dominant and the focus of the students will be to listen. By sitting down, the educator and students reside at an equal level which can be seen by the students as having an equivalent role in providing information. This is purely a psychological construct that can make a huge difference in participation and discussion.

Furthermore, teachers who wish to facilitate pupil interaction during discussion sessions would be wise to consider the U-shape design (Rosenfield, Lambert, \& Black, 1985). However, if a teacher is more concerned in having a discussion in a smaller setting with a variety of viewpoints he/she would be wise to consider a cluster arrangement.

\subsection{Cluster Arrangement}

The second seating arrangement examined is the cluster format in which students are seated in small groups of three or more.

Similar to the U-shape design, the cluster facilitates social interaction. However, both produce a 
greater number of on-task out-of-order comments, on-task oral responses, and other on-task behaviours (Rosenfield, Lambert, \& Black, 1985). As far as hand-raising, there is found to be more hand-raising in clusters than the U- shape Pupils seated in clusters, who are actively involved in class discussion, raise their hand to get attention, whereas those in the U-shape simply make more on-task out-of-order comments (Rosenfield, Lambert, \& Black, 1985).

\subsubsection{Interaction}

Interaction with cluster seating is a little different than with $\mathrm{U}$-shaped seating. In U-shaped seating the students participate as part of a large community, with cluster seating, students listen to instruction as in traditional row seating, but operate within a small community. This can be beneficial to shy students or students who wish not to talk in a larger group. Also, the smaller group allows students an opportunity to formulate beliefs, receive feedback, and practice voicing their thoughts before opening up to the whole class. In this way, interaction can first be within a smaller safe area before moving to the larger arena.

\subsubsection{Atmosphere}

The atmosphere in a cluster class is like that of countries inside a continent. Students feel a part of a larger group, but are mainly responsible to the main group they occupy. The atmosphere in the classroom provides safety for students via the groups they are within. This allows students to be free to make more mistakes, venture to unknown concepts, and even receive help from others more knowledgeable without the feeling of shame. It's an atmosphere that can create opportunities for safe learning.

\subsubsection{Behaviour}

Behaviour can be an issue with cluster seating. Whereas U-shaped seating allows the eyes of many to control the behaviour of one, the isolated small group of a larger class doesn't afford the same benefits. Students with behavioral problems may feel immune from the small group expectations and believe they can hide their actions from the larger group easily. So the social pressure is not there. On the other hand, responsible students may take control and force the student with behavioral issues to conform.

A strategy for controlling students with behavioral problems is to sit them in the center of the room. Depending on the size of the class room and the number of groups, it is best to place those students near the middle where the educator's attention is mostly focused. Do not place the students on the left or right in the front, as this is the most overlooked place by teachers. Have the students feel they are in the visual field of the educator at all times.

\subsection{Row Arrangement}

Traditional rows are very well known because almost every teacher grew up sitting in this style of seating. Similar to a military type of approach where students were lined up rank and file, it still continues today in countless schools across the world. However, when trying to facilitate individual on-task behaviour as Wheldall and Lam (1987) did in a special school for behaviourally troubled children, they encouraged the use of rows to produce desired pupil and teacher behaviour. They found that on- task behaviour doubled when seats were changed from clusters to a row formation and the teacher's positive comments also rose dramatically (Wheldall\&Lam,1987). In a situation where the teacher wishes to involve students interactively, desks arranged in rows produces a greater number of withdrawal responses and off-task responses (Wheldall\& Lam, 1987). Children at desks in rows are least likely to interact with lesson material (Rosenfield, Lambert, \& Black, 1985).

\subsubsection{Interaction}

This style is to direct focus on the teacher and isolate students so they can focus on what is being taught. The focus is not on having students interact, but if interaction does occur and it's not approved by the educator, it can easily be noticed and thwarted. However, when student to student interaction is warranted, the choices are to have one student turn around to another in the same line- which is not comfortable for the student turning around; or have the students turn their desk facing the row next to them.

\subsubsection{Atmosphere}

The atmosphere this creates is a military controlled environment. Students consciously or subconsciously understand that interaction is not encouraged as they can only view the students on their sides and the back of the student in front. Students are isolated in an undefined area which makes 
the atmosphere in the classroom controlled in the sense that everyone's attention is directed to the front. It is quite restrictive and the students have little opportunity to participate or take control of their learning.

\subsubsection{Behaviour}

This type of seating arrangement does nothing to encourage proper behaviour. Students easily become disengaged and most will find ways to entertain themselves. In this style, students in the mid to back rows can easily blend into the background by hiding behind the person in front. This allows the student to doodle, write notes, or even attempt conversations when they think it is safe.

A way to keep students with behavioural problems in line is to place them in front, but if there are a large number of students with behavioural problems, then putting them all together in a general area can quickly cause problems. If there are a couple of students who cause most of the trouble and a few who cause occasional trouble, then it might be best to place the worst offenders in front of the class where the educator's presence can curtail some of the problems.

\section{MeThodology}

This study aims at describing the importance ofseating arrangements as an effective means to improve interactions in EFL beginner class. We have chosen to use a qualitative approach to examine the correlation between the ways learners' desks or seats are disposed and the effect of this arrangement on EFL learners' participation in class activities. Two types of questionnaires were elaborated and distributed to 400 beginners EFL students and100 teachers randomly selected in 3private and 3 stateowned secondary schools located in Cotonou. The questionnaire addressed to EFL teachers consisted of open-ended questions addressing the different types of seating arrangement used by EFL teachers in their classes as well as their gains for both teachers and learners. Secondly, the open-ended questions try to examine the EFL learners' perception about the relationship between EFL learners' seating arrangement and their students' performances. The questionnaire addressed to EFL learners is made up with some open-ended questions aiming at collecting data about types of seating arrangement used by their teachers and their preferences. Analysis of the data collected were carried out following Creswell (1998)'s spiral approach.

\section{RESUlts}

In line with the design of the questionnaire, the data collected will be reported as regard to: 1) Seating arrangement practised by EFL teachers and their classroom implications according to both teachers and learners; 2) Correlation between EFL students' seating arrangement and learners' interaction.

\subsection{The Results Related to Students' Questionnaire}

Table1. Students' common seating arrangement

\begin{tabular}{|l|l|l|l|l|}
\hline $\mathbf{N}^{\circ}$ & Questions & \multicolumn{2}{|l|}{ Frequency } & \multicolumn{2}{l|}{} \\
\cline { 3 - 5 } & What is the current seating arrangement in your classroom? & U-shape & Rows & Clusters \\
\hline \multirow{2}{*}{1} & First year students & 0 & 50 & 150 \\
\cline { 2 - 5 } & Second year students & 0 & 34 & 166 \\
\cline { 2 - 5 } & TOTAL & 0 & 84 & 316 \\
\hline & Percentage & 0 & 21 & 79.00 \\
\hline
\end{tabular}

Table 1 shows that U-shape seating arrangement is not adopted by EFL teachers with their EFL beginner students and all the students who received the questionnaire have confirmed it. In addition, $21 \%$ of the students said that they commonly seat in row arrangement and $79 \%$ indicated that they commonly seat in clusters.

Table2. Frequency of Variation about EFL Students Seating Arrangement

\begin{tabular}{|l|l|l|l|l|}
\hline $\mathbf{N}^{\circ}$ & How often are you asked to change your seating arrangement? & Answers & \multicolumn{4}{|l|}{} \\
\hline 2) & \multicolumn{2}{|l}{ Always } & Often & Rarely \\
\cline { 2 - 5 } & First year EFL students & 0 & 57 & 143 \\
\cline { 2 - 6 } & Second year EFL students & 0 & 33 & 167 \\
\cline { 2 - 6 } & Total & 0 & 90 & 310 \\
\cline { 2 - 6 } & Percentage & 0 & 22.5 & 77.5 \\
\hline
\end{tabular}


Seating Arrangements as a Means for Improving Interactions in EFL Beginner Classes: The Case of Some Secondary Schools in Littoral Region

The results in table 2 show that both first and second year EFL students recognised that they are often asked by their teachers to modify the arrangements of desks before class started. $22.5 \%$ of them said that they often were asked to change their seating arrangement. However, $77.5 \%$ of them declared that they were rarely told to change their seating arrangement.

Table3. EFL Students' Preference about seating arrangement

\begin{tabular}{|c|c|c|c|}
\hline $\mathbf{N}^{\circ}$ & Which seating arrangement do you prefer the most? & Frequency & Percentage \\
\hline \multirow{3}{*}{3} & Rows seating & 52 & 13.00 \\
\cline { 2 - 4 } & Clusters seating & 343 & 85.75 \\
\cline { 2 - 4 } & U-shape arrangement & 5 & 1.25 \\
\hline \multicolumn{2}{|c|}{ Total } & 400 & 100 \\
\hline
\end{tabular}

The results in table 3 show that students do not feel much at ease when they are asked to seat in rows seating; only $13 \%$ of the EFL students were keen on such a seating arrangement. Whereas students as this seating-type is commonly used during summative evaluations, the students' responses may reflect their general attitude towards evaluation. Moreover, a great number of the EFL learners involved in the study $(85.75 \%)$ said that they were more motivated to learn when learning occurs within a cluster seating framework. Obviously, many students prefer clusters seating because it enables more interaction among students compared to other types of seating arrangement. Moreover, U-shape seating arrangement seemed unknown to EFL students probably because their teachers do not practise it.

\subsection{The Results Related to EFL Teachers' Questionnaire}

Table4. EFL Teachers Qualification and Experience

\begin{tabular}{|c|c|c|c|}
\hline \multicolumn{2}{|c|}{} & Frequency & Percentage \\
\hline \multirow{3}{*}{ Qualification } & Professional qualification & 27 & $27 \%$ \\
\cline { 2 - 4 } & Academic qualification & 73 & $73 \%$ \\
\hline \multirow{3}{*}{ Experience } & Five years or more & 24 & $24 \%$ \\
\cline { 2 - 4 } & Less than five years & 76 & $76 \%$ \\
\hline
\end{tabular}

According to table 4 , only $27 \%$ of the teachers involved in the study were professionally qualified whereas $73 \%$ of them have an academic qualification; which means that an increasing number of EFL secondary school teachers were not trained for the teaching job. Moreover, these untrained EFL teachers (76\%) were very young in the teaching job and have less than five years of experience in teaching.

In all educational system, teachers play a vital role as they implement curriculum through designing activities related to teaching goals. That is the reason why EFL teachers must not only be academically and professionally trained but they must also be well-experienced and must enjoy adequate living conditions. The downfall of students' achievement in Benin is also due to the quality of teacher recruitment. The school authorities play a great role in this situation.

Table5. Seating Arrangement Adopted by EFL Teachers with their Students

\begin{tabular}{|c|c|c|c|}
\hline $\mathbf{N}^{\circ}$ & What Seating Arrangement do you practise in your classroom? & \multicolumn{2}{|c|}{ Answers } \\
\hline \multirow{4}{*}{1} & & Frequency & Percentage \\
\cline { 2 - 4 } & Rows seating arrangement & 5 & 5.00 \\
\cline { 2 - 4 } & U-shape seating arrangement & 2 & 2 \\
\cline { 2 - 4 } & Cluster seating arrangement & 93 & 95.00 \\
\hline Total & 100 & 100 & Total \\
\hline
\end{tabular}

The results in table 5 show that $5 \%$ of EFL teachers involved in the present study made their learners seat in rows whereas $92 \%$ of them adopted cluster seating arrangement; meanwhile $2 \%$ of the teachers made seat students in U-shape seating organisation.

Table6. The Frequency of Students' Seating Arrangement Variation

\begin{tabular}{|c|c|c|c|}
\hline $\mathbf{N}^{\circ}$ & Question & \multicolumn{2}{|c|}{ Answers } \\
\hline \multirow{3}{*}{2} & How often do you vary your students' seating arrangements? & Frequency & Percentage \\
\cline { 2 - 4 } & Once a lesson & 0 & 0 \\
\cline { 2 - 4 } & Once a week & 0 & 0 \\
\cline { 2 - 4 } & Once a month & 7 & 7.00 \\
\cline { 2 - 4 } & Once a trimester & 93 & 93.00 \\
\cline { 2 - 4 } & Total & 100 & 100.00 \\
\hline
\end{tabular}


In table 6 , the results show that no teacher varied his/her students' seating arrangement within a week time $7 \%$ of them altered their learners seating disposition once a month. However, a large number of the teachers investigated (93\%) said that they change their students' seating arrangement once a trimester. The results presented in the table above indicated that almost all the EFL learners were used to changing their students' seating arrangement. In actual fact, during classroom evaluations, students are put in rows because they are very often individually evaluated and such a disposition prevents them from glancing at their counterparts' work. Based on the data presented in the table 6 , apart from the period of evaluation when students seat in rows, a large number of EFL teachers adopt cluster seating arrangement in their classes throughout the academic years.

Table7. Seating arrangement in which students' interaction increases.

\begin{tabular}{|l|l|c|c|}
\hline $\mathbf{N}^{\circ}$ & \multicolumn{1}{|c|}{ Question } & \multicolumn{2}{c|}{ Answers } \\
\hline \multirow{3}{*}{} & What Seating Arrangement best improves Students interaction? & Frequency & Percentage \\
\cline { 2 - 4 } & Rows seating arrangement & 8 & $8.00 \%$ \\
\cline { 2 - 4 } & U-shape seating arrangement & 2 & $2.00 \%$ \\
\cline { 2 - 4 } & Cluster seating arrangement & 90 & $90.00 \%$ \\
\cline { 2 - 4 } & Total & 100 & $100.00 \%$ \\
\hline
\end{tabular}

The results in table 7 show that students' interactions increase when they are seated in cluster $(90 \%)$, followed by the row seating arrangement $(8 \%)$. On the contrary, the U-shape seating arrangement is unknown to many EFL teachers (2\%).

\subsection{Discussions of the Results}

The discussion of the results will be mainly organised around the type of seating arrangement practised by EFL teachers, and the correlation between learners' seating arrangement $t$ and their interaction within the classroom.

\subsubsection{Types of seating Arrangement Practised by Beninese EFL Teachers}

According to the present study, almost all the teacher participants (98\%) recognised the importance of seating arrangement as a core variable of an effective classroom management and an essential parameter of language learning process. In the same vein, Stevick (1980) stated that "success in learning a language depends less on materials, techniques and language analysis and more on what goes on inside and between people in the classroom. aware of this reality, it is necessary, from time to time, to ponder over what goes on inside the individuals in the classroom and between them".

Three types of seating arrangement (U-shape, rows and clusters) are practised in a varying frequency by EFL teachers. As a result, $90 \%$ of the EFL teachers declared that they frequently disposed their learners' desks in clusters. These teachers' responses were confirmed by a large majority of students (93\%) who recognised that "clusters shape" as the most commonly used seating arrangement in their classrooms. This result is congruent with Berlin (1998) who concluded in his study with high school learners that "cluster seating arrangement is common in language classrooms", in fact, the cluster seating arrangement tends to produce more on-task interaction during a discussion-based format.

The second seating arrangement scored by both EFL teachers (8\%) and students (5\%) was row seating. Although this seating type is not frequently used in Beninese secondary schools; teachers resorted to it when classroom activities require some students' personal intellectual and psychological investment. Compared to cluster seating arrangement, row seating is targeting to student individual work. Zifferblatt (1972) found that "large cluster arrangements facilitate social interaction but impede individual work. Consequently, row arrangements tend to inhibit social interaction and increase independent work". A minority of the participant teachers (8\%) who adopted the row seating arrangement style justified fundamentally their choice by the type of activity and goals assigned to the lesson taught to their students. Papalia (1994) came to the same conclusion during her investigation with EFL beginner learners when she said that "the row configuration facilitates the following: the introduction of new material, the use of audio-visual aids, testing, activities where everyone is doing the same thing, independent work, and choral work".

More often studies found that rows produce more on-task behaviour for individual work. Bennet and Blundell (1983) found that the quantity of completed work increased during the use of a row arrangement. Finally, in a study, it was discovered that the amount of students' on-task behaviour rose 
between 10-29\%when seats were changed from groups to rows (Wheldall\& Lam, 1987). This does not, however, prescribe rows as the solution for all times, but only that it is the most conducive to independent work. Unfortunately, EFL secondary school teachers are not familiar with row seating arrangement which they adopted during evaluations despite its high potential for developing learners' individual competences. This situation can be accounted for EFL teacher poor teaching experience (76\%) added to lack professional training (73\%) which results in their incapacity to set appropriate teaching goals and strategies (table4).

Apart from clusters and rows seating arrangement, an insignificant number of EFL teachers (5\%) affirmed that they sometimes used "the U-shape seating design" in their classrooms. A number of reasons explained Beninese EFL teachers increasing lack of interest in such a seating. In most of the secondary schools in Benin Republic, the excessive number of students(in average 75 in beginner classes) in the classroom make it quite impossible to use such a seating arrangement. Nevertheless, teachers involved in the study acknowledged the importance of this seating organization in their language classrooms. According to them, this seating design generates a variety of advantages such as a need for an increased interaction between teacher and learners, students' concentration and instructor's mobility. This result is consistent with Papalia (1994)'s conclusion in his investigation with beginner EFL learners when he advised that "the $U$-shape design is found to facilitate the following: teacher mobility, eye contact, pupil attention, communication, game playing, and teacher control." As a matter of fact, although a great number of teachers are not trained enough to deal effectively with seating arrangement issue, they understood the role of learners' seating arrangement variation in the teaching and learning process within an EFL classroom situation.

\subsubsection{Variation of Students' Seating Arrangements}

According to the study results, EFL teachers rarely alter their students' seating scheme. Precisely, 7\% of EFL teachers change their learners seating disposition once a month whereas the remaining $93 \%$ modify it once a trimester especially during evaluations (table 6).According to the participants of the present research, the variation of students seating arrangement is mainly guided by a battery of classroom parameters including type of lessons, students' needs, and classroom environment. Similarly, Ross (1992) suggested some conditions where students seating arrangement can occur.
"Sometimes, before teachers start asking their students to move the desks all around, they make sure their preferred seating arrangement can work within the space and school furniture they have. Some configurations may not be feasible with certain classrooms. Also, they are mindful of obstructions like support beams, poles, walls and other fixtures that can't be moved. For many teachers, the chalkboard or board is a major focus in their teaching. They make sure their students can clearly see it without too much strain or difficulty. For more mobility and flexibility, their consider swapping their wall-mounted chalkboard".

The number of students in classes cannot be discounted when considering classroom seating arrangements. However, just because they have a larger class of 50 or more students doesn't mean they have to abandon their preferred desk configuration. There is a multitude of variations of each design idea to accommodate most class sizes: EFL teachers just have to be creative.

The age and maturity level of students can also hinder the choice or selection of a seating plan. When selecting a classroom setup, teachers must be aware of their students' personal traits. If you have students who display behaviour issues, be mindful of special seating considerations.

Many factors can justify this rarity of that action such as overcrowded classrooms, the reduced amount of time allocated for EFL teaching and learning per week, the small size of classrooms, and lack of professional training. At one end of the spectrum are teachers who like to change up the class seating charts on a weekly or monthly basis, believing that it's good for everyone to have a change of scenery. One of the advantages to frequent changing of seating is that if two chatty students are sitting near each other, they won't be sitting near each other for very long.

Curriculum can also help to dictate when to change seating charts. You can change seating with each semester or quarter, giving the students a symbolic fresh start. If your semesters or quarters are divided into units, change seating with the units. Or, if you're teaching a specific subject, you can 
change seating when you move on to a new lesson. This can help to signal the brain - both yours and the students' that something new has started.

But not every educator likes to change their seating chart, and that is their decision. However, if things start to feel stagnant after a few months and your classroom seating hasn't changed, consider it as an option. It's an uncomplicated way to give everyone a change of scenery. How should a teacher choose a seat for his students? Should you assign seats or allow students to choose their own seats? Some teachers think that assigning seats is the easiest way to minimize classroom problems.

Desk arrangements can vary based on classroom activities and teaching style, with options including semi-circles, tables or groups, stadium-style seating, and the standard rows. Ideally, you should be able to walk among the students while they are working. Your choices may be limited by your space and number of students, and there are ultimately advantages and disadvantages to every arrangement.

\subsubsection{The Seating Arrangement that best Improves Students' Interaction}

It appears, from the results of the investigation, that students' interaction is much more clearly noticeable when activities are done with them seating in groups or clusters. This is reinforced by the fact that there are fewer students $(8 \%)$ who do not take part in any way to class discussion while seating in rows than while seating in clusters $(90 \%)$.

Moreover, it was easier for the teacher to handle the class and get lessons through. It can then be inferred that large student participation to classroom speaking activities occurs in clusters or group seating situations. This trend was further confirmed by the findings derived from Papalia (1994) supported that clusters facilitates the following "remedial activities, tutoring, use of media, reinforcement of learned material, use of self-instructional materials, peer teaching, skit planning, games, self-pacing, teacher awareness of individual learning problems, and grouping according to interests or needs"..

Seating arrangements are very important when thinking about classroom management. The way a class should be arranged clearly depends on the type of students and the philosophies the teacher uses. Not one situation is better than another and changing the room around will change the environment. The best classroom arrangement can change depending on the way students behave in class and to each other. Rows might be very successful for one student while clusters could be for another. All students learn differently and depending on the teacher's philosophy and the way the teacher incorporates the seating during the instruction has an influence on the students in different ways. This allows the students to see class with a different perspective, working with other people and seeing information with a different angle. A teacher needs to plan each seating arrangement carefully and look at all personalities and levels of students.

Results also suggest that the nature of the academic task and type of behaviour desired should dictate this acting arrangement. Ross (1992) suggests that "generally, teachers who want to maximise the ontask behaviour of their students during independent work should consider utilising rows rather than groups as their primary seating arrangement and moving desks into other positions to facilitate interaction".

If students are working on individual assignments, they should be in a seating arrangement that makes interacting with their peers inconvenient and apparent to teachers-for example, in rows students are not directly facing each other and they may not be close enough to touch each other. When the desired behaviour is interactive, however, like brainstorming, seating arrangements that facilitate interactions by proximity and position, such as clustered desks or semi-circles, should be utilised.

\section{IMPLICATIONS}

The ideal seating arrangement is not easily defined. For example, despite some of the negative aspects of the row arrangement, teachers found it easy to monitor and assist students during individual work time. Row arrangement does not facilitate class discussions because the students at the back of the room had difficulty hearing the students at the front of the room.

From the data analysis, it is recommended that the row arrangement be used for test-taking and independent activities in which the teacher needs to assess students' learning on an individual basis. 
In these types of situations, the teacher can easily monitor students' work, and students are provided with a more conductive situation for concentration on individual work. It appears, from the results that teachers consider the goal of the lesson and match these seating arrangements accordingly. Teachers should move away from the notion of a fixed seating arrangement and remember to adjust their seats according to a specific activity. For example, if a cooperative group lesson is being taught, students should be arranged in clusters to best facilitate their learning. On the other hand, rows would be best used during a test or when students are working individually, while a U-shape arrangement can be used during a class discussion or debate.

In order to select the appropriate seating arrangement, a teacher should consider the method of instruction being used (cooperative learning, whole group discussion, etc.), the spatial design of the room, and amount and types of interaction desired. Then, a teacher can decide upon the best arrangement and have the students quickly moved their seats into the desired arrangement. By having students assist in arranging their desks, the length of time it would take the teacher to do so on his /her own is eliminated. However, for a more permanent arrangement, the teacher should continue to be responsible for the placement of the seats in order to place the students in the most appropriate location. With this information in mind, teachers will become aware that the goal of increased ontask behaviour will soon result in more learning time for all students.

If students are working on individual assignments, they should be seated in an arrangement that makes interacting with their peers inconvenient and apparent to teachers - for example, in rows students are not directly facing each other and they may not be close enough to touch each other inconspicuously. When the desired behaviour is interactive, however, like brainstorming or questioning the teacher seating arrangements that facilitate interactions by proximity and position, such as clustered desks or semi-circles, should be utilised.

Altering seating arrangements may be a way to address teacher stress and other negative feelings that impact on the classroom environment; paying attention to behavioural antecedents as a way to reduce undesired behaviour could benefit students and help to alleviate teacher anxiety.

In addition to inclusive classrooms with heterogeneous populations, seating arrangements have the potential to be a useful tool for special educators in homogeneous classrooms, perhaps especially in classrooms for students with behaviour disorders.

\section{CONCLuSiON}

There is no single classroom seating arrangement that promotes positive behavioural and academic outcomes for all tasks, because the available research clearly indicates that the nature (i.e., interactive versus independent) of the task should dictate the arrangement. Teachers, especially those who have students with special educational needs that impact on their behaviour in inclusive or homogeneous settings, should be able to eliminate many disruptions that are due to inappropriate student interactions by utilising a rows arrangement for individual tasks and moving desks together when interaction is desirable. Further studies are needed to examine the relationship between students' performance and other classroom parameters such as a classroom's location in the building, natural light from window.

\section{REFERENCES}

\section{Books}

[1] Abdelaziz M. (2011) Cooperative Learning and communicative competence. Florida: The Montessor House F.L.

[2] Bonus, M. \& Riordan, I. (1998). Increasing student on-task behaviour through the use of specific seating arrangements. Chicago, IL: Saint Xavier university.

[3] Cohen et al (2007). Research Methods in Education. Routledge Taylor \& Francis Group, London.

[4] Gagné, E.D. (1985). The Congnitive Psichology of School Learning. Boston: Little, Brown and Company.

[5] Hasting and Schwies. The effect of Seating Arrangement on Task Engagement in Primary Classrooms

[6] Johnson, D.W. \& Johson, R.T. (1994).Learning together and Alone, Cooperative, Competitive and Individualistic Learning. (4 $4^{\text {th }}$ edition). Edina; Minn. International Book.

[7] Michele Terry Thompson. Effect of Tiered Training on General Educators 
Seating Arrangements as a Means for Improving Interactions in EFL Beginner Classes: The Case of Some Secondary Schools in Littoral Region

[8] Mensah A. (2010) Classroom Management for Basic Social School Teachers, Winneba, ISBN 9988-02272-7

[9] Moyles, J.R. (1992) Organizing for Learning in the Primary Classroom; A Balanced Approach to Classroom Management. Buckingham, open press

[10] Papalia (1994): Exploration of Classroom Seating Arrangement and Student Behaviour in Second Grade Classroom.

[11] Rinehart, J. (1991). Organization of the environment. Interventions for students with emotional disorders. Austin, TX: Pro-Ed.

[12] Strong-Wilson, T., \& Ellis, J. (2007). Children and place: Reggio Emilia's environment as third teacher. Montreal, Quebec: Monthum.

[13] Wengel (1952); Seating arrangements Changing with Times

\section{Articles}

[14] Bereshford, J. (2007) "Seated and Ready to Learn Creating Quality Group Learning Experiences". CB Vol. $5 N^{\circ} 2007$.

[15] Bettenhaussen, s. (1998). "Make proactive modifications to your classroom. Intervention in school and clinic", 33(3), 182-183

[16] Gross et al (2009) "Pupil Participation in Scottish. University of Glasgow: the SACRE Centre, Research in Education”, February 2009

[17] Gardino, C,A \& Fullerton, E. (2010). "Changing behaviours by changing the classroom environment. Teaching Exceptional Children”, 42(6), 8-13

[18] MacAuley, DJ. (1990). “Classroom environment: A literature review. Educational Psychology”, 10(3); 239-253;

[19] McCorskey, J. and McVetta, R. (1978) “Classroom Seating Arrangements: communication Education”, Volume 27, March1978.

[20] Michael H. Long (1987)"Group Work in the Teaching and Learning of English as a Foreign Language _ Problems and Potentials. English Language Teaching Journal. 31:4 (July 1977, pp. 285 - 292.

[21] Weinstein, cs. (1992). "Designing the instructional environment: Focus on seating. In Proceedings of Selected Research and Development. Presentations at the Convention of the Associational communications and Technology. Bloomington": Posen.

[22] Wannarka R and Ruhl K (2003)"Seating that promotes positive Academic and Behavioural Outcomes: a review of empirical research. Support for Learning” 23 (2)

[23] Susi, F. D. (1989). "The physical environment of art classroom: a basis for discipline”. Art Education, 42(37-43.

[24] Poshansky, E \& Lambert, N. (1985). "The physical setting and open education". The school Review, 82(4), 556-574.

\section{Websites}

[25] Florman, J. (2003). Psychological \& quantitative foundations: Researching classroom seating arrangement. Accessed April, 2017, from http:// www.

[26] Education.uiowa.edu/eatiowa/fall03/department/pandq /ind ex.html (Accessed January 4, 2017)

[27] Lackney, J., \& Jacobs, P(2002). Teachers as Place markers: Investigating teacher's use of the physical learning environment in instructional design in learning styles: Unblock your true potential. (n.d.) Accessed February 4, 2017 from http://www.Learningstyles.net/index.php?option=com-content \&task=20\&Itemid=70\&lang=en

[28] Public Agenda, (2004). Teaching Interrupted: Do discipline policies in today's public schools foster the common good? New York, NY: Author. Retrieved from http// commongood.org/assets/attachments/22.pdf

[29] Richards, J. (2006). Setting the Stage for Student Engagement. Kappa Delta Phi. Record. www.eric.ed.gov (accessed March, 2017)

\section{AUTHORS' BIOGRAPHY}

Dr Pédro Marius Egounleti, born on the 12th January 1976 in Niamey (NIGER). Currently Assistant Professor, Lecturer of EFL Didactics and Business Administration at English Department of University of Abomey-Calavi, Benin, West Africa. 


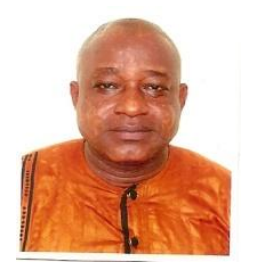

Dr Ulrich O. SènaHindémè, born on the 1stJanuary 1977 in Abomey-Calavi (BENIN). Currently Assistant Professor, Lecturer of EFL Didactics and Business Administration at English Department of University of Abomey-Calavi, Benin, West Africa.

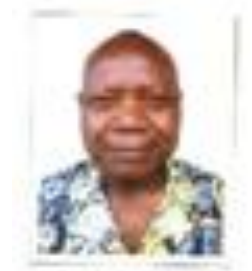

Dr Innocent C. Datondji (aplaywriter and poet), born in paouignan (BENIN). Associate Fulbright professor of linguistics and EFL Didactics. Formerly a teacher and the director of the Advanced training college of University of Abomey-Calavi, Benin, West Africa.

Citation: Ulrich O. Sèna Hindémè. "Seating Arrangements as a Means for Improving Interactions in EFL Beginner Classes: The Case of Some Secondary Schools in Littoral Region”. International Journal on Studies in English Language and Literature (IJSELL), vol 6, no.10, October 2018, pp. 20-31. doi:http://dx.doi.org/10.20431/2347-3134.0610003.

Copyright: (C) 2018 Authors. This is an open-access article distributed under the terms of the Creative Commons Attribution License, which permits unrestricted use, distribution, and reproduction in any medium, provided the original author and source are credited. 